Cita: Borges, Moisés Augusto de Oliveira.; Guerra, Laryssa Rangel.; Pereira, Janderson Francisco.; Rosa, Thiago de Souza.; Camões, José Camilo.; Ruffoni, Ricardo. (2021). Prevalência, características e fatores associados às lesões esportivas em atletas de jiu-jitsu brasileiro. Cuadernos de Psicología del Deporte, 21(2), 146-162

\title{
Prevalência, características e fatores associados às lesões esportivas em atletas de jiu-jitsu brasileiro
}

\section{Prevalencia, características y factores asociados a lesiones deportivas en atletas brasileños del jiu-jitsu}

\section{Prevalence, characteristics and factors associated with sports injuries in brazilian jiu-jitsu athletes}

\begin{abstract}
Borges, Moisés Augusto de Oliveira ${ }^{1,2}$; Guerra, Laryssa Rangel ${ }^{1,2}$; Pereira, Janderson Francisco ${ }^{3}$; Rosa, Thiago de Souza ${ }^{2,4}$; Camões, José Camilo"; Ruffoni, Ricardo ${ }^{2,5}$

${ }^{1}$ Mestrando do Programa de Pós-Graduação em Psicología da UFRRJ; ${ }^{2}$ Grupo de Estudos e Pesquisa em Gestão do Esporte (GEPGE) da UFRRJ; ${ }^{3}$ Graduando em Educação Física da UFRRJ; ${ }^{4}$ Doutorando do Programa de Pós-Graduação em Psicología da UFRRJ; ${ }^{5}$ Professor Adjunto do Departamento de Educação Física e Desportos da UFRRJ.
\end{abstract}

\section{RESUMO}

Objetivo: determinar a ocorrência e características de lesões musculoesqueléticas e osteoarticulares em atletas de Jiu-Jitsu Brasileiro (BJJ). Método: Foi aplicado um questionário fechado para 146 atletas de BJJ acerca das lesões sofridas, autodiagnosticadas ou diagnosticadas clinicamente, nos últimos 12 meses. Os dados foram analisados pelo programa SPSS $\odot$ 20.0. Resultados: No total, foram relatadas 403 lesões sofridas. A maioria dos atletas participantes dessa pesquisa são do nível iniciante, sendo a faixa de graduação azul a de maior tamanho amostral (43,15\%). O grupo etário de 18 a 28 anos $(50,68 \%)$ foi o que relatou o maior número de lesões (53,35\%). Além disso, observouse que a maior parte dos atletas treina entre 2 e 6 horas por semana $(65 \%)$, sendo essa parcela da amostra a mais acometida por lesões (246 no total). Em geral, o joelho foi a área mais afetada $(25,1 \%)$ e a luxação de dedos a lesão mais frequente $(12,7 \%)$. Dentre outros resultados encontrados, destaca-se que, quanto maior a carga horária de treinamento semanal, menor o risco de lesões $(r=-0,85)$. Assim como que, quanto maior a idade do atleta, maior a frequência de lesões $(r=0,93)$. Destaca-se que as lesões ocorreram, em grande parte, durante os treinamentos $(81,5 \%)$, sendo a maioria de natureza grave (58\%).

Palavras-chave: Lutas; Artes Marciais; Alto Rendimento; Dano Muscular; Treinamento.

\section{RESUMEN}

Objetivo: determinar la ocurrencia y características de lesiones musculoesqueléticas y osteoarticulares en atletas brasileños de Jiu-Jitsu (BJJ). Método: Se aplicó un cuestionario cerrado a 146 atletas de BJJ sobre las lesiones sufridas, autodiagnosticadas o diagnosticadas clínicamente, en los últimos 12 meses. Los datos se analizaron con el programa SPSS @ 20.0. Resultados: En total, se reportaron 403 heridos. La mayoría de los atletas que participan en esta investigación se encuentran en el nivel principiante, y el rango de graduación azul tiene el tamaño de muestra 


\title{
Borges et al.
}

más grande $(43,15 \%)$. El grupo de edad entre 18 y 28 años $(50,68 \%)$ fue el que reportó mayor número de lesiones $(53,35 \%)$. Además, se observó que la mayoría de los deportistas entrena entre 2 y 6 horas semanales (65\%), siendo esta parte de la muestra la más afectada por lesiones (246 en total). En general, la rodilla fue la zona más afectada $(25,1 \%)$ y la luxación de los dedos fue la lesión más frecuente $(12,7 \%)$. Entre otros resultados encontrados, es de destacar que cuanto mayores son las horas semanales de entrenamiento, menor es el riesgo de lesiones $(r=-0,85)$. Además, cuanto mayor es el deportista, mayor es la frecuencia de lesiones $(r=0,93)$. Es de destacar que las lesiones ocurrieron, en gran medida, durante el entrenamiento (81,5\%), la mayoría de las cuales fueron de carácter grave $(58 \%)$.

Palabras clave: Luchas; Artes marciales; Alto rendimiento; Daño muscular; Entrenamiento.

\begin{abstract}
Objective: to determine the occurrence and characteristics of musculoskeletal and osteoarticular injuries in Brazilian Jiu-Jitsu (BJJ) athletes. Method: A closed questionnaire was applied to $146 \mathrm{BJJ}$ athletes about the injuries suffered, self-diagnosed or clinically diagnosed, in the last 12 months. The data were analyzed using the SPSS $\odot 20.0$ program. Results: In total, 403 injuries were reported. Most of the athletes participating in this research are at the beginner level, with the blue graduation range having the largest sample size (43.15\%). The age group between 18 and 28 years old $(50.68 \%)$ was the one that reported the highest number of injuries $(53.35 \%)$. In addition, it was observed that most athletes train between 2 and 6 hours per week $(65 \%)$, with this portion of the sample being the most affected by injuries (246 in total). In general, the knee was the most affected area $(25.1 \%)$ and finger dislocation was the most frequent injury $(12.7 \%)$. Among other results found, it is noteworthy that the higher the weekly training hours, the lower the risk of injuries $(r=-0.85)$. As well as that, the older the athlete, the greater the frequency of injuries $(r=$ $0.93)$. It is noteworthy that the injuries occurred, to a large extent, during training $(81.5 \%)$, the majority of which were severe in nature $(58 \%)$.
\end{abstract}

Keywords: Fights; Martial arts; High yield; Muscle damage; Training.

\section{INTRODUÇÃO}

O Jiu-Jitsu Brasileiro (BJJ) é um esporte de autodefesa, baseado no princípio de derrotar o adversário ao subjugá-lo usando sua própria força, mediante chaves de articulação, imobilizações, quedas e estrangulamentos (Reis et al., 2015). O BJJ é uma prática esportiva de exercícios anaeróbios intensos e que requer alto nível de condicionamento físico ( $\mathrm{Da}$ Silva et al., 2014; Reis et al., 2015), concentração e equilíbrio (Andreato et al., 2015). Além do alto nível de estresse e competitividade característicos do esporte de rendimento (Tomé-Lourido et al., 2019). Por ser uma arte marcial de combate intermitente, que tem como principal objetivo a defesa pessoal, atletas de BJJ são constantemente expostos a situações de elevado risco de lesões. Em grande parte, devido as técnicas de chaves de articulação, quedas e choques frequentes (Reis et al., 2015; Jensen et al., 2017).

Nessa perspectiva, pesquisas recentes destacaram a alta prevalência de lesões musculoesqueléticas e osteoarticulares em atletas de BJJ (das Graças et al., 2017; Da Silva Junior et al., 2018). Em alguns casos, com prevalência de lesão superior à $90 \%$ (Souza et al., 2011; Machado, Machado, Marchi, 2012). Quanto a ocorrência de lesões, as articulações dos joelhos, ombros e cotovelos foram apontadas como as áreas mais comumente lesadas, sendo a ocorrência da grande maioria destas lesões durante as sessões de treinamento (Scoggin et al., 2014; Da Silva Junior et al., 2018). Além disso, atletas experientes demonstraram um risco maior de lesões em comparação com atletas menos experientes (Kreiswirth, Myer, Rauh, 2014; Da Silva Junior et al., 2018), embora que ainda não seja clara a associação entre taxa de lesões e o nível de experiência no BJJ.

As lesões esportivas são preocupações constantes na carreira dos atletas, clubes e equipes técnicas, não somente pela possibilidade de interrupção no treinamento e, por consequência, do processo evolutivo do esportista em busca da melhor performance (Ortega et al., 2014; Hammami et al., 2017), mas também pelo impacto no bem-estar psicológico do atleta (Robbins et al., 2019). Assim, estudos sobre a ocorrência de lesões são fundamentais para identificar os mecanismos de trauma, a fim de 


\section{Prevalência de lesões em atletas de jiu-jitsu}

realizar um trabalho preventivo mais eficaz. Dentre os diversos estudos sobre características e fatores associados as lesões esportivas, destacam-se os relacionados aos esportes de combate, como a Luta Olímpica (Montero et. al, 2018), o Taekwondo (Olmedilla-Caballero et al., 2020), o Karatê (Arriaza et al., 2016), o Judô e as Artes Marciais Mistas (MMA) (Bledsoe et al., 2006; Lam, Kaufman, 2013). No entanto, há uma escassez de dados sobre lesões no BJJ (Petrisor et al., 2019).

Nesse sentido, a partir de uma ótica fisiopatológica, são necessários estudos epidemiológicos que identifiquem a incidência, prevalência e etiologia das lesões de atletas de BJJ, uma vez que a ocorrência de lesões pode ser de ordem multifatorial (Bahr; Krosshaug, 2005; Gárcia, Más, 2011). Desta forma, especialmente em função de lacunas na literatura existente, espera-se que, a partir dos resultados obtidos neste estudo, sejam levantadas informações importantes para ampliar os saberes teóricos na área da psicologia do esporte e ciências do esporte, para fornecer mais informações para atletas, técnicos, preparadores físicos e membros da comunidade científica.

Por conseguinte, espera-se contribuir para ampliar os conhecimentos sobre as características e fatores associados às lesões esportivas, subsidiando a intervenção de pesquisadores e profissionais da área, seja na elaboração de um trabalho de prevenção dessas lesões e/ou melhor planejamento e periodização dos treinamentos, com objetivo fim de minimizar o quantitativo de lesões característicos desta prática.

Assim, o presente estudo tem como objetivo determinar a ocorrência e as características de lesões musculoesqueléticas e osteoarticulares em atletas de BJJ. Trabalhamos com as hipóteses de que, (I) o joelho será apontado como a região mais acometida por lesões (Usuki et al., 2017); (II) que a maior parte das lesões ocorreu durante o treinamento (Petrisor et al., 2019); e (III) que existe uma relação proporcional entre a experiência, o tempo de prática e a incidência de lesões em atletas de BJJ (Moriarty, Charnoff, Felix, 2019).

\section{METODOLOGIA}

Este é um estudo descritivo, retrospectivo e correlacional, com abordagem quantitativa.
Descritivo, pois apresenta resultados que descrevem fatos e fenômenos de determinada realidade. Retrospectivo, pois busca a reconstrução de informações sobre os indivíduos em determinado momento ou momentos do passado. E correlacional, por explorar, estabelecer e quantificar as relações entre as variáveis. (Lima, 2011; Ato, Lópes, Benavente, 2013).

\section{Participantes}

A amostra inicial do estudo foi composta por 178 atletas masculinos, com idade entre 18 e 50 anos, com, no mínimo, 12 meses de treinamento voltado para o alto rendimento e filiados a uma equipe profissional de BJJ. Foram excluídos da pesquisa os esportistas com menos de um ano de prática, os que não participaram de, ao menos, uma competição profissional nos últimos 12 meses, atletas portadores de doenças musculoesqueléticas e lesões osteoarticulares não relacionadas à prática esportiva, atletas praticantes de outras modalidades de lutas além do BJJ, e aqueles que estivessem afastados do treinamento por outras razões não ligadas à prática do esporte. Desta forma, foram considerados 146 atletas de BJJ.

\section{Aspectos éticos}

Os procedimentos deste estudo estão de acordo com os padrões éticos da Declaração de Helsinque de 1975 (WMA, 2000; Bošnjak, 2001; Tyebkhan, 2003), que estabelece os princípios éticos fundamentais para a pesquisa envolvendo seres humanos. Ainda, este estudo segue as normas éticas previstas quanto à assinatura dos Termos de Consentimento Livre e Esclarecido (TCLE), sendo informado aos participantes que apareceriam em anonimato. $\mathrm{O}$ presente estudo foi aprovado por um comitê de ética pelo processo 23083.009176/2019-78, protocolo $\mathrm{n}^{\circ}$ $1.317 / 19$.

\section{Procedimentos e coleta de dados}

Para a realização do presente estudo, aplicou-se um questionário fechado que foi respondido pelos atletas. O questionário de 26 perguntas abordou questões como: tempo de prática do esporte, quantas sessões de treinamento por semana, quantas horas de treinamento por dia, quantas lesões já sofreu, em quais partes do corpo e qual o tipo de lesão, se a lesão ocorreu novamente, se foi proveniente de próprio golpe ou 


\section{Borges et al.}

golpe adversário, qual foi o golpe aplicado ou recebido, se a lesão ocorreu durante competição ou treinamento, quando tempo ficou, se já treinou sentindo dores e/ou competiu estando lesionado e se isso agravou a lesão e se era de conhecimento do praticante esta possibilidade.

Foi solicitado ao participante que relatasse todas as lesões sofridas, autodiagnosticadas ou diagnosticadas clinicamente, nos últimos 12 meses. Somente foram consideradas as lesões ocorridas durante treinamento e competição amadora ou profissional de BJJ. A coleta de dados ocorreu entre os meses de outubro e dezembro de 2019.

\section{Análise estatística}

A análise dos dados foi feita de forma quantitativa, por meio de estatística descritiva. Os dados foram tratados por meio da estatística inferencial (média, desvio padrão e frequência percentual) sendo os mesmos analisados pelo programa SPSS $\odot$ 20.0. O coeficiente de Spearman (r) foi utilizado para averiguar a correlação entre taxa de lesão (TL) por faixa etária do atleta, NL por horas semanais de treinamento, TL por faixa de graduação do atleta, incidência de lesões provenientes de movimentação por faixa de graduação do atleta, incidência de lesões provenientes de próprio golpe por faixa de graduação do atleta e incidência de lesões provenientes de golpe do adversário por faixa de graduação do atleta.

\section{RESULTADOS}

A amostra estudada foi composta por 146 atletas de BJJ, todos do sexo masculino, com idade média de 29,76 anos e faixa etária de 18 a 50 anos. Outras características da amostra podem ser vistas na Tabela 1.

Tabela 1. Características descritivas da amostra.

\begin{tabular}{ccc}
\hline \multicolumn{1}{c}{ VARIÁVEL } & $\mathrm{n}$ & $\%$ \\
\hline IDADE & & \\
$18-28$ & 74 & $50,7 \%$ \\
$29-39$ & 54 & $36,9 \%$ \\
$40-50$ & 18 & $12,4 \%$ \\
LADO DOMINANTE M. SUPERIOR & & \\
$\quad$ Direito & 130 & $88,9 \%$ \\
Esquerdo & 16 & $10,9 \%$
\end{tabular}

LADO DOMINANTE M. INFERIOR
Direito

120

$82,2 \%$

Esquerdo

26

$17,8 \%$

NÍVEL DO ATLETA

Iniciante (faixas de graduação

Branca e Azul)

93

$63,7 \%$

Avançado (faixas de

graduação Roxa, Marrom e

Preta)

53

$36,3 \%$

FAIXA DE GRADUAÇÃO DO

ATLETA

\begin{tabular}{lll} 
Branca & 31 & $21,3 \%$ \\
Azul & 63 & $43,2 \%$ \\
Roxa & 28 & $19,2 \%$ \\
Marrom & 14 & $9,6 \%$ \\
Preta & 10 & $6,7 \%$ \\
\hline
\end{tabular}

Legenda: $\mathrm{n}=$ número de atletas; $\%=$ Porcentagem.

Na tabela 2 são apresentados os dados retrospectivos da ocorrência de lesão nos últimos 12 meses.

Tabela 2. Dados retrospectivos da ocorrência de lesão nos últimos 12 meses.

\begin{tabular}{|c|c|c|}
\hline VARIÁVEL & $\mathrm{n}$ & Porcentagem \\
\hline \multicolumn{3}{|l|}{ SOFREU LESÃO NOS } \\
\hline \multicolumn{3}{|l|}{ ÚLTIMOS 12 MESES } \\
\hline Sim & 133 & $91,1 \%$ \\
\hline Não & 13 & $8,9 \%$ \\
\hline \multicolumn{3}{|l|}{ TREINOU SENTINDO DORES } \\
\hline Sim & 114 & $40,0 \%$ \\
\hline Não & 32 & $60,0 \%$ \\
\hline \multicolumn{3}{|l|}{ COMPETIU ESTANDO } \\
\hline \multicolumn{3}{|l|}{ LESIONADO } \\
\hline Sim & 73 & $50,0 \%$ \\
\hline Não & 73 & $50,0 \%$ \\
\hline \multicolumn{3}{|l|}{ POR COMPETIR ESTANDO } \\
\hline \multicolumn{3}{|l|}{ LESIONADO } \\
\hline $\begin{array}{l}\text { Agravou a lesão, mas o } \\
\text { atleta sabia que isso poderia } \\
\text { acontecer }\end{array}$ & 13 & $17,0 \%$ \\
\hline $\begin{array}{l}\text { Agravou a lesão, mas o } \\
\text { atleta não sabia que isso } \\
\text { poderia acontecer }\end{array}$ & 5 & $7,0 \%$ \\
\hline $\begin{array}{l}\text { Não agravou a lesão, mas o } \\
\text { atleta sabia que isso poderia } \\
\text { acontecer }\end{array}$ & 37 & $51,0 \%$ \\
\hline
\end{tabular}




\section{Prevalência de lesões em atletas de jiu-jitsu}

Não agravou a lesão, mas o atleta não sabia que isso poderia acontecer

Legenda: $\mathrm{n}=$ número de atletas; $\%$ = Porcentagem.

O relato de lesão sofrida dos participantes pode ser encontrado na Figura 1 (Apêndice 1) e a distribuição geral das áreas acometidas por lesões é mostrada na Figura 2. No total, foram relatadas 403 lesões sofridas nos últimos 12 meses. Destas, 325 (80,6\%) foram diagnosticadas clinicamente pela avaliação de um especialista e $78 \quad(19,4 \%)$ foram autodiagnosticadas, não tendo o atleta procurado atendimento médico especializado.

Na Tabela 3 pode-se observar a incidência de lesão por faixa etária dos atletas divididos em quatro colunas: de 18 a 28 anos, de 29 a 39 anos e de 40 a 50 anos. A maior concentração dos atletas desta pesquisa está na faixa de 18 a 28 anos (50,68\%), sendo esta, inclusive, a faixa que concentra o maior NL (53,35\%). Além disso, observou-se que o momento mais comum para ocorrência de lesões foi durante o treinamento $(81,50 \%)$, tanto na faixa de 18 a 28 anos $(87,32 \%)$, quanto na de 29 a 39 anos $(97,87 \%)$ e na de 40 a 50 anos $(73,33 \%)$. Em cada faixa etária a área mais afetada e a lesão mais comum foram diferentes.
De acordo com a Tabela 4 , constatou-se que a maior parte dos atletas treina entre 2 e 6 horas por semana (65\%), sendo também a faixa mais acometida por lesões (246 no total). A maior TL por 1000 horas de exposição está na faixa de $\leq 2$ horas, enquanto a menor TL por 1000 horas está na faixa de $>6 \leq 8$ horas semanais.

Tabela 4. Incidência de lesão por horas semanais de treinamento.

\begin{tabular}{lcccc}
\hline HST & $\mathrm{n}$ & $\%$ & $\mathrm{NL}$ & $\mathrm{TL} / 1000 \mathrm{~h}$ \\
\hline$\leq 2 \mathrm{~h}$ & 8 & $5,5 \%$ & 17 & 26,4 \\
$>2 \mathrm{~h} \mathrm{e} \leq 4 \mathrm{~h}$ & 46 & $31,5 \%$ & 141 & 18,8 \\
$>4 \mathrm{~h} \mathrm{e} \leq 6 \mathrm{~h}$ & 49 & $33,5 \%$ & 105 & 8 \\
$>$ 6h e $\leq 8 \mathrm{~h}$ & 14 & $9,6 \%$ & 36 & 5,5 \\
$>8 \mathrm{~h} \mathrm{e} \leq 10 \mathrm{~h}$ & 15 & $10,3 \%$ & 53 & 7,4 \\
$>10 \mathrm{~h}$ & 14 & $9,6 \%$ & 51 & 6,9 \\
\hline
\end{tabular}

Legenda: HST = Horas semanais de treinamento; \% = Porcentagem; NL = Número de lesões; TL/1000h $=$ Taxa de lesão por 1000 horas de exposição.

Tabela 3. Incidência de lesão por idade.

\begin{tabular}{lccc}
\hline & \multicolumn{3}{c}{ Faixa etária } \\
\cline { 2 - 4 } Variáveis & $18-28$ & $29-39$ & $40-50$ \\
\hline $\mathrm{n}$ & 74 & 54 & 18 \\
$\mathrm{NAL}$ & $71(96 \%)$ & $47(87 \%)$ & $15(83,3 \%)$ \\
$\mathrm{NL}$ & 215 & 141 & 47 \\
TL/1000h & 8,8 & 9,2 & 11,2 \\
MCOL & Treinamento (62) & Treinamento (46) & Treinamento (11) \\
ACOL & Joelho (44) & Dedos (30) & Joelho (11) \\
LC & Luxação de ombro (27) & Luxação de dedo (25) & Entorse de joelho (7) \\
\hline
\end{tabular}

Legenda: NAL = Número de atletas lesionados; NL = Número de lesões; TL/1000h = Taxa de lesão por 1000 horas de exposição; MCOL = Momento mais comum de ocorrência de lesão; ACOL = Área mais comum de ocorrência de lesão; LC = Lesão mais comum. 


\section{Borges et al.}

A maioria dos atletas participantes dessa pesquisa são do nível iniciante (Tabela 5), sendo a faixa de graduação azul a de maior tamanho amostral $(43,15 \%)$. Dos atletas de faixa de graduação marrom e preta, todos alegaram ter sofrido lesão nos últimos 12 meses, sendo uma média de 3,35 e 4,5 lesões por atleta, respectivamente. Ao analisar a incidência de lesão por faixa de graduação do atleta, apurou-se que, com exceção dos iniciantes faixa de graduação branca, a região do joelho foi a mais afetada por lesões. Nesse sentido, destaca-se que todos os atletas de faixa de graduação preta acusaram terem sofrido lesão na região do joelho, embora que a lesão mais comum neste grupo tenha sido luxação de ombro. adversário por faixa de graduação do atleta (C6). Assim, em $\mathrm{C} 1$, o r foi de 0,93 , ou seja, correlação linear muito forte (Figura 3). Em C2 e C6 (Figuras 4 e 8), o $\mathrm{r}$ foi de - 0,85 e 0,75, respectivamente, apresentando forte correlação linear. Já em C3 (Figura 5), o r de - 0,16 indica correlação linear muito fraca. Por fim, as correlações C4 e C5 (Figuras 6 e 7), apresentaram, respectivamente, correlação linear fraca $(\mathrm{r}=0,30)$ e moderada $(\mathrm{r}=0,44)$. (Apêndice 2$)$

Tabela 5. Incidência de lesão por faixa do atleta.

\begin{tabular}{lccccc}
\hline \multirow{2}{*}{ Variáveis } & \multicolumn{2}{c}{ Faixas de graduação nível iniciante } & \multicolumn{3}{c}{ Faixas de graduação nível avançado } \\
\cline { 2 - 6 } & Branca & Azul & Roxa & Marrom & Preta \\
\hline $\mathrm{n}$ & 31 & 63 & 28 & 14 & 10 \\
Idade & $29 \pm 8,1$ & $28,2 \pm 8,1$ & $31,5 \pm 8,9$ & $32,4 \pm 10$ & $33,1 \pm 6,2$ \\
$\mathrm{TP}$ & $2,1 \pm 1,3$ & $3,9 \pm 2,2$ & $8,1 \pm 3,2$ & $12,1 \pm 9,3$ & $14 \pm 4,4$ \\
$\mathrm{NAL}$ & $26(83,9 \%)$ & $58(92,1 \%)$ & $25(89,3 \%)$ & $14(100 \%)$ & $10(100 \%)$ \\
$\mathrm{NL}$ & 80 & 152 & 79 & 47 & 45 \\
$\mathrm{TL} / 1000 \mathrm{~h}$ & 11,9 & 8 & 9,8 & 9,6 & 10,4 \\
MCOL & Treinamento (54) & Treinamento (23) & Treinamento (24) & Treinamento (10) & Treinamento (8) \\
ACOL & Dedos (32) & Joelho (11) & Joelho (17) & Joelho (9) & Joelho (10) \\
LC & Luxação de Dedo & Luxação de Ombro & Luxação de Dedo & Entorse de Tornozelo & Luxação de Ombro \\
& $(30)$ & $(5)$ & $(11)$ & $(4)$ & $(7)$
\end{tabular}

Legenda: TP = Tempo de prática $($ anos; média $\pm \mathrm{Dp}) ; \mathrm{NAL}=$ Número de atletas lesionados; $\mathrm{NL}=$ Número de lesões; TL $/ 1000 \mathrm{~h}=\mathrm{Taxa}$ de lesão por 1000 horas de exposição; MCOL = Momento mais comum de ocorrência de lesão; ACOL = Área mais comum de ocorrência de lesão; LC = Lesão mais comum.

A Tabela 6 apresenta, com base no relato dos atletas, dados retrospectivos da lesão mais recente. Assim, foi possível reunir mais informações a respeito da origem das lesões, causa, efeitos, tratamento realizado pelos atletas e se a lesão já havia ocorrido antes e, por isso, reincidente.

O coeficiente de Spearman (r) foi utilizado para verificar a correlação entre a TL/1000 horas de exposição por faixa etária do atleta $(\mathrm{C} 1)$, do NL por horas semanais de treinamento (C2), da TL por faixa de graduação do atleta (C3), da incidência de lesões provenientes de movimentação por faixa de graduação do atleta (C4), da incidência de lesões provenientes de próprio golpe por faixa de graduação do atleta (C5) e da incidência de lesões provenientes de golpe do
Tabela 6. Dados retrospectivos da lesão mais recente

\begin{tabular}{lcc}
\hline VARIÁVEL & $\mathrm{n}$ & $\%$ \\
\hline A ÚLTIMA LESÃO FOI PROVENIENTE DE & & \\
Técnica aplicada & 20 & $15 \%$ \\
Técnica recebida & 54 & $40,6 \%$ \\
Movimentação & 59 & $44,4 \%$ \\
TÉCNICA APLICADA OU RECEBIDA & & \\
Arm Lock & 37 & $27,9 \%$ \\
Leg Lock & 24 & $18 \%$ \\
Triângulo & 13 & $9,8 \%$ \\
Raspagem & 24 & $18 \%$ \\
Queda & 26 & $19,5 \%$ \\
Outros & 9 & $6,8 \%$ \\
FICOU AFASTADO DO TREINAMENTO & & \\
Sim & 108 & $74 \%$ \\
Não & 38 & $26 \%$
\end{tabular}




\section{Prevalência de lesões em atletas de jiu-jitsu}

DIAS AFASTADO DO TREINAMENTO

\begin{tabular}{lcc} 
De 1 a 7 dias & 12 & $11 \%$ \\
De 8 a 14 dias & 6 & $6 \%$ \\
De 15 a 30 dias & 27 & $25 \%$ \\
De 31 a 60 dias & 39 & $36 \%$ \\
Mais de 61 dias & 24 & $22 \%$ \\
\hline
\end{tabular}

Legenda: $\mathrm{n}=$ número de atletas; $\%$ = Porcentagem. que os demais grupos etários $(0,45$ lesões por atleta a mais em relação a faixa de $22-27$ anos). Em nosso estudo, a TL da faixa etária de 40 - 50 anos foi de, aproximadamente, 11 lesões a cada 1000 horas de exposição, sendo $17,85 \%$ maior que a TL do grupo da faixa etária de 29 - 39 anos e 21,42\% maior que a do grupo de $18-28$ anos.

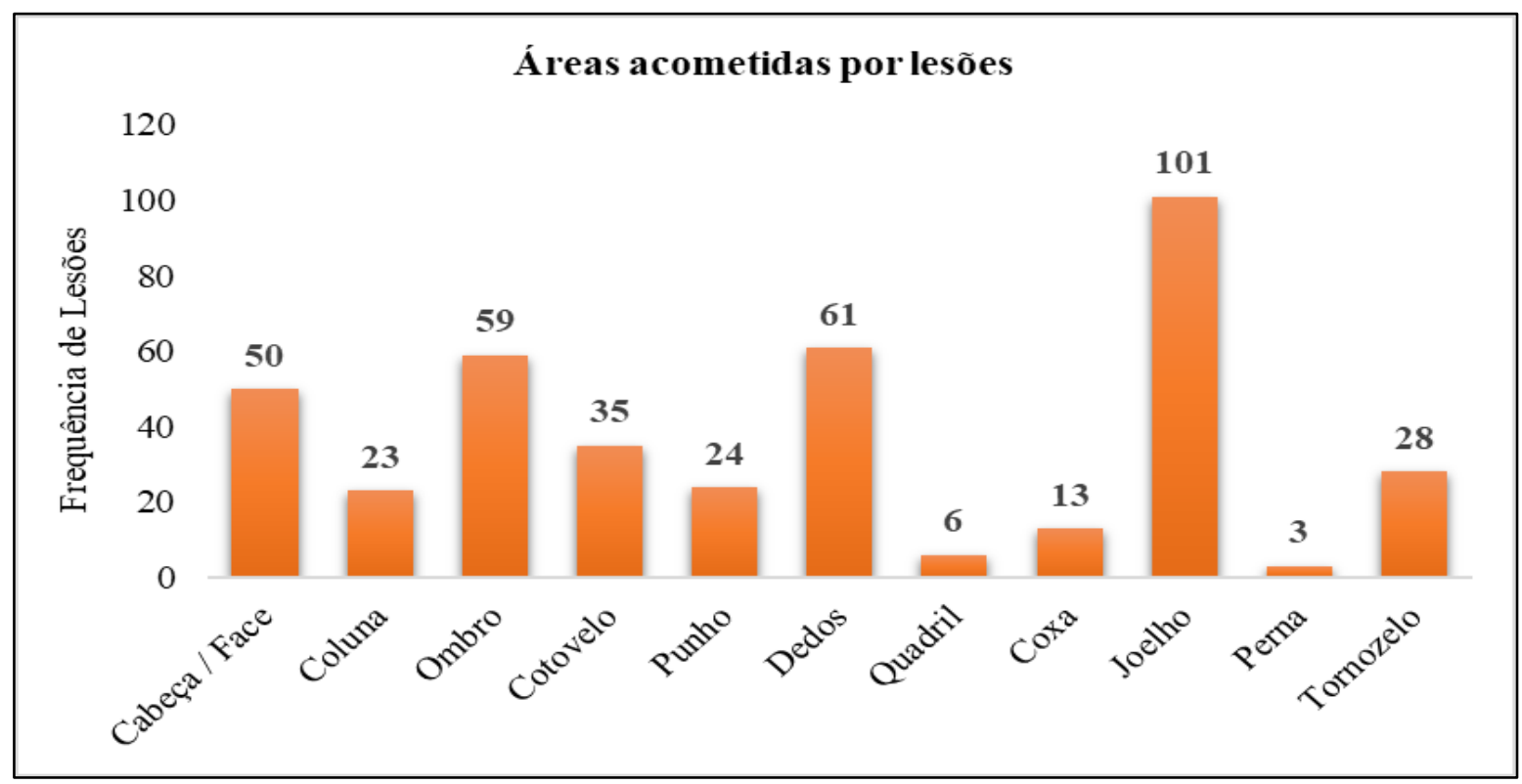

Figura 2. Áreas acometidas por lesões.

\section{DISCUSSÃO}

Este estudo teve como objetivo determinar a ocorrência e características de lesões musculoesqueléticas e osteoarticulares em atletas de BJJ. Assim, foi encontrada uma prevalência de lesão musculoesquelética de $91,1 \%$ nos atletas participantes desta pesquisa, sendo esse resultado similar aos achados de outros estudos, os quais também relataram elevadas taxas de lesões (Souza et al., 2011; Machado, Machado, Marchi, 2012).

Outro ponto importante desta investigação foi verificar a existência de correlação entre variáveis. Em $\mathrm{C} 1$, o parâmetro $\mathrm{r}$ foi de 0,93 , indicando correlação linear muito forte. Ou seja, quanto maior a idade do atleta, maior o NL sofridas e mais propenso a sofrer lesões ele é. Nossos achados são consistentes com o relato de pesquisa de Das Graças et al. (2017), onde o grupo master (32 - 38 anos) apresentou maior ocorrência de lesões e alterações musculoesqueléticas
Com o passar dos anos, é natural que ocorram diversas alterações funcionais, bioquímicas e morfológicas no indivíduo (Knoplich, 2001). Em função do processo dinâmico e progressivo do envelhecimento, verificase o declínio gradual das aptidões físicas, com o enfraquecimento muscular, a redução no desempenho físico, na habilidade motora, na capacidade de concentração, de reação e de coordenação, além da redução da capacidade cardiorrespiratória e do equilíbrio (Papaléo Netto, 2002; Pires et al., 2002; Moraes, Moraes, Lima, 2010). Essas alterações podem explicar a queda no rendimento esportivo e, consequentemente, a maior incidência de lesão, justamente pela "perda da eficiência nos processos envolvidos na manutenção da homeostase do organismo aumentando a vulnerabilidade ao estresse e diminuição da viabilidade" (Camboim et al., 2017, p. 2416).

Nesta investigação, os atletas na faixa de 18 - 28 anos foram expostos, em média, por volta de 330 horas de 


\section{Borges et al.}

prática de BJJ nos 12 meses que antecederam esta pesquisa, enquanto a faixa etária de 29 - 39 anos teve média de 282 horas de exposição e a faixa de 40 - 50 anos 197 horas. De fato, autores evidenciaram que os atletas mais jovens tendem a apresentar maior carga horária semanal de treinamento do que as demais faixas etárias (das Graças et al., 2017). No entanto, não foram encontrados outros estudos que tenham associado a quantidade de treino semanal com a quantidade de lesões.

A partir da análise desta variável, percebe-se que, quanto menor a carga horária semanal de treinamento dos atletas, maior a TL/1000 horas de exposição (C2, $r=-0,85)$. Ou seja, para a amostra estudada, maior volume de treinamento significa menor TL. A destacar, a TL/1000 horas de exposição do grupo que declarou treinar menos de 2 horas por semana foi de, aproximadamente, 26 lesões, enquanto a TL/1000 horas de exposição dos atletas que treinam mais de 10 horas por semana foi quatro vezes menor. Como uma possível justificativa para este resultado, supõe-se que os atletas com baixa carga horária semanal de treinamento não realizem fortalecimento muscular, o que explicaria a alta TL/1000 horas de exposição, uma vez que o baixo condicionamento físico está associado à alta incidência de lesões no esporte (Da Silva et al., 2014).

Diante disso, destaca-se a importância do fortalecimento muscular e o trabalho entre treinadores, preparadores físicos e atletas para desenvolver a resiliência dos atletas, com o propósito de prevenir ocorrências de esgotamento dos atletas e reduzir o quantitativo de lesões (Da Silva et al., 2014; Moen et al., 2019). Cabe ressaltar que, independentemente da carga horária de treino, o atleta irá apresentar lesões, como destacado neste estudo (Tabela 4). Nesse sentido, 119 dos 146 atletas participantes (81,5\%) relataram que a última lesão ocorreu durante treinamento, enfatizando o potencial lesivo das sessões de treinamento de BJJ (Petrisor et al., 2019).

Estudos apontam que a maioria das lesões de praticantes de artes marciais ocorre durante o período de treinamento (Moriarty, Charnoff, Felix, 2019). No estudo de Petrisor et al. (2019), mais de 90\% dos praticantes de BJJ sofreram lesões durante o treinamento. Nesta pesquisa, analisando por grupo etário, 73,3\% dos atletas da faixa etária de 40 - 50 anos afirmaram ter se lesionado durante o treinamento, com prevalência de $83,3 \%$. No grupo da faixa etária de 29 - 39 anos, o percentual de atletas lesionados é de $97,87 \%$, com prevalência de $87 \%$. Já na faixa etária de $18-28$ anos, a prevalência foi de $96 \%$. O alto índice de lesões relatadas nessa faixa etária pode ser, em parte, relacionado à pouca experiencia no esporte, o que os leva a ferir com mais frequência a cabeça, região da face e dedos ao tentar executar ou se desvencilhar de um golpe (Moriarty, Charnoff, Felix, 2019).

Nesse sentido, observou-se que $55,6 \%$ das lesões relatadas foram provenientes de golpes aplicados ou recebidos. Nessa perspectiva, Nunes et al. (2017), apontam que as chaves de articulação são as técnicas mais lesivas do BJJ, devido à força aplicada em excessiva amplitude articular no momento do golpe. Nesta investigação, as técnicas Arm Lock (chave de braço) e Leg Lock (chave de perna) sobressaem como as técnicas mais lesivas (45,9\%), sendo as luxações articulares as lesões mais frequentes.

Ainda, estudos sugerem que a incidência de lesões em lutadores é maior nos membros inferiores do que nos membros superiores, independente da faixa de graduação, do tempo de prática ou experiência dos atletas no esporte (Machado, Machado, Marchi, 2012; Nunes et al., 2017). Contrapondo esses resultados, nesta investigação foram relatadas 171 lesões nos membros superiores $(42,4 \%), 163$ nos membros inferiores $(40,5 \%)$ e 69 na cabeça, pescoço ou tronco $(17,1 \%)$. Apesar disso, fora percebido que, no geral, a região mais acometida por lesões foi a do joelho (Figura 2), seja analisando a amostra como um todo, separando por faixa etária ou por cor de faixa de graduação (Nunes et al., 2017).

Pesquisas recentes evidenciaram que a articulação do joelho tende a ser a região do corpo mais acometida por lesões esportivas. No presente estudo, $25,1 \%$ do total de lesões relatadas ocorreu no joelho, indo ao encontro à suposição inicial. Este resultado é consistente com os achados em outros estudos, como de Moriarty, Charnoff e Felix (2019), Machado, Machado e Marchi (2012) e Usuki et al. (2017), que encontraram percentuais de 20,8\%, 28\% e 26,5\%, respectivamente. Aliás, os dedos e ombros foram a segunda e terceira áreas mais afetadas por lesões (McDonald et al., 2017; das Graças et al., 2017). Drury et al. (2017) também identificaram um alto índice de lesões nos dedos e punho de atletas de BJJ. 


\section{Prevalência de lesões em atletas de jiu-jitsu}

Em C4 e C5, não foram encontradas forte correlação linear entre as variáveis. No entanto, em $\mathrm{C} 3$, ao verificar a correlação entre a TL e a faixa de graduação do atleta (Figura 5), o parâmetro r de 0,81 indicou forte correlação linear. Portanto, existe forte tendência de que o avançar na graduação de faixas no BJJ resulte em maior incidência de lesão por atleta (Da Silva Junior et al., 2018). Corroborando com essa afirmativa, em C6 foi observada forte correlação linear entre a faixa de graduação do atleta e a incidência de lesões sofridas provenientes de golpes do adversário (r $=0,75)$. Não somente isso, foi encontrada maior incidência de lesões em atletas avançados (Kreiswirth, Myer, Rauh, 2014), sendo diretamente proporcional ao tempo de prática de BJJ (Tabela 5), sustentando a suposição inicial de relação proporcional entre a experiência no BJJ, tempo de prática e a incidência de lesões (Moriarty, Charnoff, Felix, 2019). Não foi observada

Ademais, Carvalho, Grecco e Oliveira (2003) identificaram que $65 \%$ do total de lesões esportivas relatadas ocorreu em atletas de nível avançado/veterano. Destaca-se que todos os atletas de faixa de graduação marrom e preta deste estudo relataram ter sofrido, ao menos, uma lesão nos últimos 12 meses, sendo a taxa média de lesões dos atletas avançados de, aproximadamente, quatro lesões por atleta, enquanto nos atletas iniciantes a taxa média foi de cerca de três lesões por atleta.

Com base nesses resultados, cogita-se a hipótese de que o maior índice de lesões em atletas mais experientes esteja relacionado com o nível técnico dos adversários enfrentados durante os treinamentos e competições, uma vez que os confrontos são estabelecidos conforme a faixa de graduação do atleta (Diaz-Lara et al., 2014). Ainda, a literatura aponta que atletas mais experientes de BJJ (faixas de graduação roxa e preta) apresentam níveis mais elevados de força muscular de membros inferiores e de preensão manual do que atletas menos experientes, possivelmente, em razão do maior domínio corporal, coordenação motora global e propriocepção, decorrentes da acentuada experiencia motora (Diaz-Lara et al., 2014).

No mais, atletas de nível avançado costumam participar de um número maior de competições em comparação com atletas iniciantes, o que viria a contribuir para a alta prevalência de lesões neste grupo (das Graças et al., 2017). Supõe-se então que a ocorrência de lesões esteja diretamente relacionada com a vivência do atleta no esporte (Da Silva Junior et al., 2018).

Outro ponto interessante deste estudo é a análise com base nos dados retrospectivos da lesão mais recente. Dessa forma, constatou-se que 108 dos atletas afirmaram ter se afastado da prática esportiva devido a lesão. Destes, 58\% ficaram mais de 31 dias afastados, valor que equivale à lesão classificada como severa, ou seja, mais de quatro semanas de afastamento do treinamento ou hospitalização (Machado, Machado, Marchi, 2012). Nesses casos, uma das possíveis consequências da interrupção do treinamento é a perda do processo evolutivo do atleta em função do processo de descondicionamento físico, que leva a perda parcial ou completa do desempenho e das adaptações morfológicas, fisiológicas e funcionais promovidas pela prática regular de exercícios físicos (Ortega et al., 2014; Santiago et al., 2019).

Além disso, 78,1\% dos atletas declararam ter treinado mesmo sentindo dores. De acordo com Cangussu et al. (2007), dor é um sintoma que pode levar à queda do rendimento físico ou afastamento dos atletas por tempo indeterminado. Porém, por se tratar de uma percepção subjetiva, pode existir percepção de dor mesmo sem ser constatada a lesão por meios clínicos (Silva, Rabelo, Rúbio, 2010). A destacar, 50\% da amostra relatou já ter competido mesmo estando lesionado, o que reforça a ideia de que é comum o entendimento dos atletas de que precisam ser mais resistentes à dor para obter a melhor performance. Esse entendimento, combinado aos fatores motivacionais da disputa de um campeonato, pode levá-los a ignorar a presença de dor, com o risco de resultar em uma lesão ou de agravar uma lesão já existente (Wiese-Biornstal, 2010).

Nesse sentido, 68\% dos atletas que competiram estando lesionados afirmaram saber que isso poderia agravar a lesão, o que reflete o pensamento dos atletas de que $o$ sofrimento é necessário para o desenvolvimento de suas capacidades físicas, para melhorar o desempenho esportivo e para alcançar a vitória, muitas vezes incentivado pelo treinador, ainda mais com a alta competitividade característica desta prática (Souza et al., 2011; Moura et al., 2013). Como resultado, $24 \%$ dos atletas relataram que a lesão se 


\section{Borges et al.}

agravou pelo fato de terem competido estando lesionados.

Este estudo apresenta algumas limitações. Dentre elas, o designer da pesquisa. Os resultados dependiam de relatórios precisos dos sujeitos acerca das lesões sofridas nos últimos 12 meses. Além do mais, embora tenha sido possível estimar essa taxa com base nos relatos dos atletas, essa estimativa não é precisa, pois não considerou o tempo de afastamento da prática devido às lesões e possíveis outras ausências dos treinos ao longo dos últimos 12 meses. Por fim, o histórico de lesões do atleta foi autorrelatado e foi determinada a etiologia apenas da última lesão individual sofrida.

\section{APLICAÇÕES PRÁTICAS}

A partir deste estudo, atletas, técnicos e profissionais envolvidos com o BJJ podem elaborar estratégias e medidas preventivas adaptadas para cada nível de experiência em BJJ, com base em uma melhor compreensão da taxa de incidência de lesões, a fim de reduzir o potencial lesivo desta prática. Para tanto, deve-se atentar especialmente aos atletas iniciantes que possuem maior tendência em se lesionar na cabeça, face e extremidades, muitas vezes tentando se defender ou desvencilhar de algum golpe de maneira equivocada. Além disso, este estudo é um dos poucos que correlacionaram o tempo de treinamento semanal com a incidência de lesões. Assim, verificou-se que, quanto maior o volume de treinamento semanal, menor o risco de lesões.

Nessa perspectiva, os resultados apontam que atletas menos experientes tendem a apresentar um menor NL sofridas. Ainda, haja vista a intensidade do desporto, o baixo condicionamento físico parece ser um dos fatores associados à alta incidência de lesões no esporte. Cabe ressaltar a importância de a equipe instruir o atleta a não ignorar os sinais de seu corpo a respeito de possíveis lesões, pelo risco de se agravarem pelo treinamento ou competição. (conscientização e equipe multidisciplinar).

\section{REFERÊNCIAS}

1. Andreato, L. V., Julio, U. F., Gonçalves Panissa, V. L., Del Conti Esteves, J. V., Hardt, F., Franzói de Moraes, S. M., Oliveira de Souza, C., Franchini, E. (2015). Brazilian Jiu-Jitsu Simulated
Competition Part II: Physical Performance, TimeMotion, Technical-Tactical Analyses, and Perceptual Responses. Journal of strength and conditioning research, 29(7), 2015-2025. https://doi.org/10.1519/jsc.0000000000000819

2. Arriaza, R., Inman, D., Arriaza, A., Saavedra, M. A. (2016). Low Risk of Injuries in Young Adolescents Participating in Top-Level Karate Competition. The American Journal of Sports Medicine, 44(2), 305-308. https://doi.org/10.1177/0363546515615577

3. Ato, M., López, J. J., Benavente, A. (2013). Un sistema de clasificación de los diseños de investigación en psicología. Anales de Psicología, 29(3), 10381059. https://dx.doi.org/10.6018/analesps.29.3.17 8511

4. Bahr, R., Krosshaug, T. (2005). Understanding injury mechanisms: a key component of preventing injuries in sport. British journal of sports medicine, 39(6), 324-329. https://doi.org/10.1136/bjsm.2005.018341

5. Bledsoe, G. H., Hsu, E. B., Grabowski, J. G., Brill, J. D., Li, G. (2006). Incidence of injury in professional mixed martial arts competitions. J Sport Sci Med, 5(CSSI-1), 136-142.

6. Bošnjak S. (2001). The Declaration of Helsinki the cornerstone of research ethics. Arch Oncol, 9(3): 179-84.

7. Camboim, F. E. F., Nóbrega, M. O., Davim, R. M. B., Camboim, J. C. A., Nunes, R. M. V., Oliveira, S. X. (2017). Benefícios da atividade física na terceira idade para a qualidade de vida. Revista enfermagem, 11(6), 2415-2422.

8. Cangussu, D. F. R., Rodrigues, D. C. M., Reis, D., Venturini, C. (2007). Estudo da associação entre dor e desempenho funcional do membro superior de jogadores de vôlei. Revista Brasileira de Ciências e Movimento, 15(4), 15-20.

9. Carvalho, J. P., Grecco, L. H., Oliveira. A. R. (2013). Prevalência de lesões em praticantes de 


\section{Prevalência de lesões em atletas de jiu-jitsu}

jiu-jitsu: comparação entre nível iniciante e avançado. Science in Health, 4(2), 71-79.

10. Da Silva Junior, J. N., Kons, R. L., Dellagrana, R. A., Detanico, D. (2018). Injury prevalence in Brazilian jiu-jitsu athletes: Comparison between different competitive levels. Rev Bras Cineantropometria e Desempenho Humano, 20(3), 280-289. https://doi.org/10.5007/1980$0037.2018 v 20 \mathrm{n} 3 \mathrm{p} 280$

11. Da Silva, B. V., Ide, B. N., de Moura Simim, M. A., Marocolo, M., da Mota, G. R. (2014). Neuromuscular responses to simulated brazilian jiu-jitsu fights. Journal of human kinetics, 44, 249-257. https://doi.org/10.2478/hukin-20140130

12. Das Graças, D., Nakamura, L., Barbosa, F., Martinez, P. F., Reis, F. A., Oliveira-Junior, S. A. (2017). Could current factors be associated with retrospective sports injuries in Brazilian jiu-jitsu? A cross-sectional study. BMC sports science, medicine rehabilitation, 9(16). https://doi.org/10.1186/s13102-017-0080-2

13. Diaz-Lara, F. J., García, J. M. G., Monteiro, L. F., Abian-Vicen, J. (2014). Body composition, isometric hand grip and explosive strength legsimilarities and differences between novice and experts in an international competition of Brazilian jiu jitsu. Arch Budo, 10(1), 211-217.

14. Drury, B. T., Lehman, T. P., Rayan, G. (2017). Hand and Wrist Injuries in Boxing and the Martial Arts. Hand Clin. Hand Clinics, 33(1), 97-106. https://doi.org/10.1016/j.hcl.2016.08.004

15. Folscher, L. L., Grant, C. C., Fletcher, L., Janse van Rensberg, D. C. (2015). Ultra-Marathon Athletes at Risk for the Female Athlete Triad. Sports medicine - open, 1(1), 29. https://doi.org/10.1186/s40798-015-0027-7

16. Gárcia, R. L., Más, A. G. (2011). Percepción de dolor y fatiga em relácion com el estado de ánimo. Cuardenos de Psicologia del Deporte, 11(2), 93106.
17. Hägglund, M., Waldén, M. (2016). Risk factors for acute knee injury in female youth football. Knee surgery, sports traumatology, arthroscopy: official journal of the ESSKA, 24(3), 737-746. https://doi.org/10.1007/s00167-0153922-z

18. Hammami, N., Hattabi, S., Salhi, A., Rezgui, T., Queslati, M., Bouassida, A. (2017). Combat sport injuries profile: A review. Science and Sports, $33(2)$, 73-79. https://doi.org/10.1016/j.scispo.2017.04.014

19. Jensen, A. R., Maciel, R. C., Petrigliano, F. A., Rodriguez, J. P., Brooks, A. G. (2017). Injuries Sustained by the Mixed Martial Arts Athlete. Sports health, 9(1), 64-69. https://doi.org/10.1177/1941738116664860

20. Kim, K. S., Park, K. J., Lee, J., Kang, B. Y. (2015). Injuries in national Olympic level judo athletes: an epidemiological study. British journal of sports medicine, 49(17), 1144-1150. https://doi.org/10.1136/bjsports-2014-094365

21. Knoplich, J. (2001). Viva bem com a coluna que você tem: dores nas costas, tratamento e prevenção. São Paulo: Ibrasa.

22. Kreiswirth, E. M., Myer, G. D., Rauh, M. J. (2014). Incidence of injury among male Brazilian jiujitsu fighters at the World Jiu-Jitsu No-Gi Championship 2009. Journal of athletic training, 49(1), 89-94. https://doi.org/10.4085/1062-6050-49.1.11

23. Lam, J., Kaufman, M. (2013). Comparison of injuries in martial arts and combat sports: a crosssectional approach. J Investig Med, 61, 137-138.

24. Lima, D. V. M. (2011). Desenhos de pesquisa: uma contribuição para autores. Online Brazilian Journal of Nursing, 10(2), 1-14.

25. Machado, A. P., Machado, G. P., Marchi, T. (2012). Prevalência de lesões no Jiu-Jitsu de acordo com histórias de dois atletas participantes em dois campeonatos mundiais em 2006. ConScientiae Saúde, 11(1), 85-93. https://doi.org/10.5585/conssaude.v11n1.3033 


\section{Borges et al.}

26. McDonald, A. R., Murdock, F. A., McDonald, J. A., Wolf, C. J. (2017). Prevalence of injuries during brazilian jiu-jitsu training. Sports, 5(2), 39. https://doi.org/10.3390/sports5020039

27. Moen, F., Hrozanova, M., Stiles, T., Stenseng, F. (2019). A aliança de trabalho na relação técnicoatleta e o esgotamento do atleta $\mathrm{O}$ papel mediador da resiliência do atleta. International Journal of Sport Psychology, 50(4), 338-355.

28. Montero, F. J. O., Bascuñana, M. L. M., Mena, L., Rus, T. I., Gullón, J. M. L. (2018). Análisis cualitativo sobre aspectos psicológicos y rendimiento deportivo en Lucha Olímpica. Revista de Psicología Aplicada al Deporte y al Ejercicio Físico. 3(2), 1-19. https://doi.org/10.5093/rpadef2018a12

29. Moriarty, C., Charnoff, J., Felix, E. R. (2019). Injury rate and pattern among Brazilian jiu-jitsu practitioners: A survey study. Physical therapy in sport: official journal of the Association of Chartered Physiotherapists in Sports Medicine, 39, 107-113. https://doi.org/10.1016/j.ptsp.2019.06.012

30. Moura, P. V., Silva, E. A. P., Silva, P. P. C., Freitas, C. M. S., Caminha, I. O. (2013). O significado da dor física na prática do esporte de rendimento. Revista Brasileira de Ciências do Esporte, 35(4), 1005-1019. https://doi.org/10.1590/s010132892013000400013

31. Nunes, R. de A. M., Ribeiro, C. C., Alves, L. R., Carvalho, I. L. da S., Vale, R. G. de S. (2017). Prevalência de lesões em praticantes de Jiu-Jitsu: um estudo descritivo. Journal of Physical Education, 86(1). https://doi.org/10.37310/ref.v86i1.208

32. Olmedilla-Caballero, B., Moreno-Fernández, I. M., Gómez-Espejo, V., Olmedilla-Zafra, A (2020). Preparación psicológica para los Juegos Paralímpicos y afrontamiento de lesión: un caso en taekwondo. Revista de Psicología Aplicada al Deporte y al Ejercicio Físico, 5(2), 1-13. https://doi.org/10.5093/rpadef2020a4
33. Ortega, F. Z., Gárcia, R. F, Zagalaz, J. C., Girela, D. L., Cortés, A. J. P. (2014). Aspectos psicosomáticos implicados en las lesiones deportivas. Cuadernos de Psicología del Deporte, 14(2), 81-88. https://doi.org/10.4321/s157884232014000200009

34. Papaléo Netto, M. (2002). Gerontologia: a velhice e o envelhecimento em visão globalizada. São Paulo: Atheneu.

35. Petrisor, B. A., Fabbro, G. D., Madden, K., Khan, M., Joslin, J., Bhandari, M. (2019). Injury in brazilian jiu-jitsu training. Sports Health, 11(5), 432-439.

https://doi.org/10.1177/1941738119849112

36. Pires, T. S., Nogueira, J. L., Rodrigues, A., Amorim, M. G., Oliveira, A. F. (2002). A recreação na terceira idade. Cooperativa do fitness.

37. Reis, F. J., Dias, M. D., Newlands, F., MeziatFilho, N., Macedo, A. R. (2015). Chronic low back pain and disability in Brazilian jiu-jitsu athletes. Physical therapy in sport: official journal of the Association of Chartered Physiotherapists in Sports Medicine, 16(4), 340-343. https://doi.org/10.1016/j.ptsp.2015.02.005

38. Robbins, B., Pfeifer, J., Trounson, J., Skues, J. (2019). The psychological well-being of professional male athletes: a qualitative study of adversity factors in the workplace and response trendsta. International Journal of Sport Psychology, 50(4), 295-319.

39. Scoggin, J.F., Brusovanik, G., Izuka, B.H., Rilland, E.Z., Geling, O., Tokumura, S. (2014). Assessment of Injuries During Brazilian Jiu-Jitsu Competition. Orthopaedic Journal of Sports Medicine, 2(2). https://doi.org/10.1177/2325967114522184

40. Silva, E. M., Rabelo, I., Rubio, K. (2010). A dor entre atletas de alto Rendimento. Revista Brasileira de Psicologia do Esporte, 3(4), 79-97. https://doi.org/10.31501/rbpe.v3i1.9287 


\section{Prevalência de lesões em atletas de jiu-jitsu}

41. Souza, J. M. C., Faim, F. T., Nakashima, I. Y., Altruda, C. R., Medeiros, W. M., Silva, L. R. (2011). Lesões no Karate Shotokan e no Jiu-Jitsu: trauma direto versus indireto. Revista Brasileira de Medicina do Esporte, 17(2), 107-110. https://doi.org/10.1590/s1517-

86922011000200007

42. Tomé-Lourido D., Arce, C. \& Ponte, D. (2019). The relationship between competitive state anxiety, self-confidence and attentional control in athletes. Revista de Psicología del Deporte/Journal of Sport Psychology, 28(2), 143160 .

43. Tyebkhan, G. (2003) Declaration of Helsinki: the ethical cornerstone of human clinical research. Indian J Dermatol Venereol Leprol, 69(3), 245-247.

44. Usuki, H., Rosen, A., Jawed-Wessel, S., Grandgenett, N., McGrath, M. (2017). Injury history, severity, and medical care for athletes participating in Brazilian jiujitsu. Journal of Athletic Training, 52(6), S153.
45. Vanderlei, F. M., Bastos, F. N., Tsutsumi, G. Y., Vanderlei, L. C., Netto Júnior, J., Pastre, C. M. (2013). Characteristics and contributing factors related to sports injuries in young volleyball players. BMC research notes, 6, 415. https://doi.org/10.1186/1756-0500-6-415

46. Wiese-Bjornstal D. M. (2010). Psychology and socioculture affect injury risk, response, and recovery in high-intensity athletes: a consensus statement. Scandinavian journal of medicine science in sports, 20 Suppl 2, 103-111. https://doi.org/10.1111/j.16000838.2010.01195.x

47. WMA (2000). Press Release: WMA revises the Declaration of Helsinki. 9 October. 


\section{Borges et al.}

\section{APÊNDICE 1}

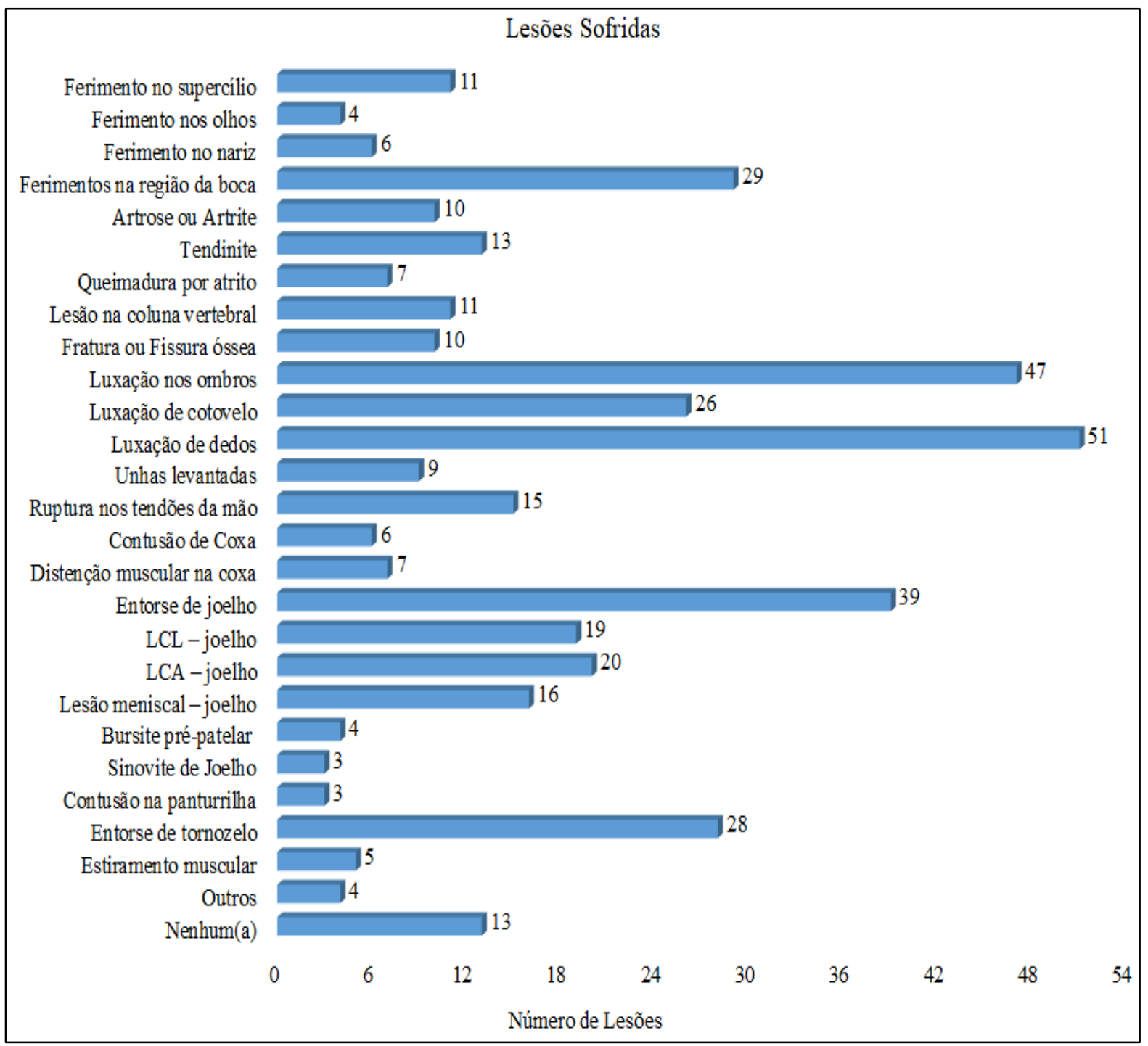

Figura 1. Incidência de lesões. 
Prevalência de lesões em atletas de jiu-jitsu

APÊNDICE 2

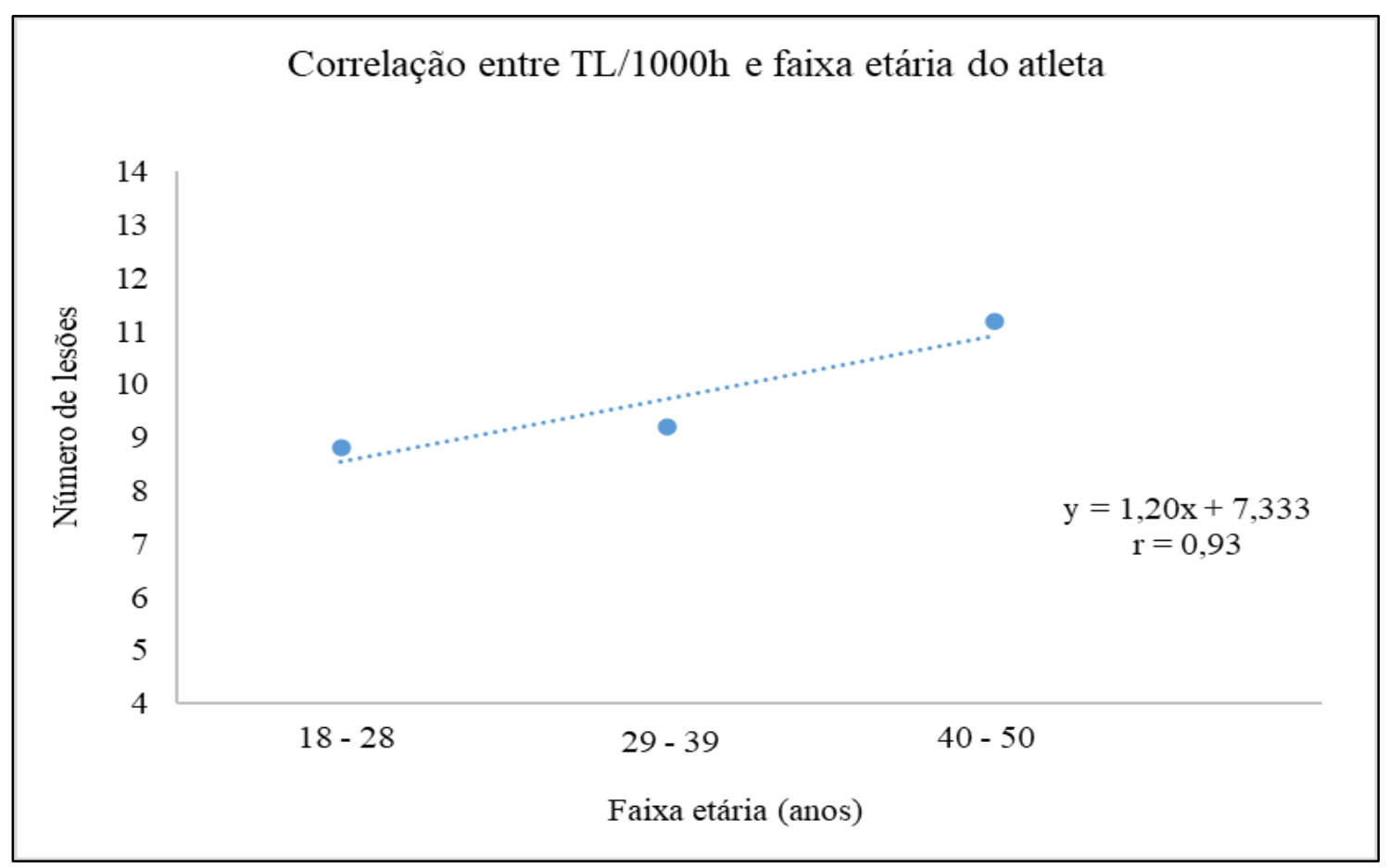

Figura 3. Correlação taxa de lesão por faixa etária.

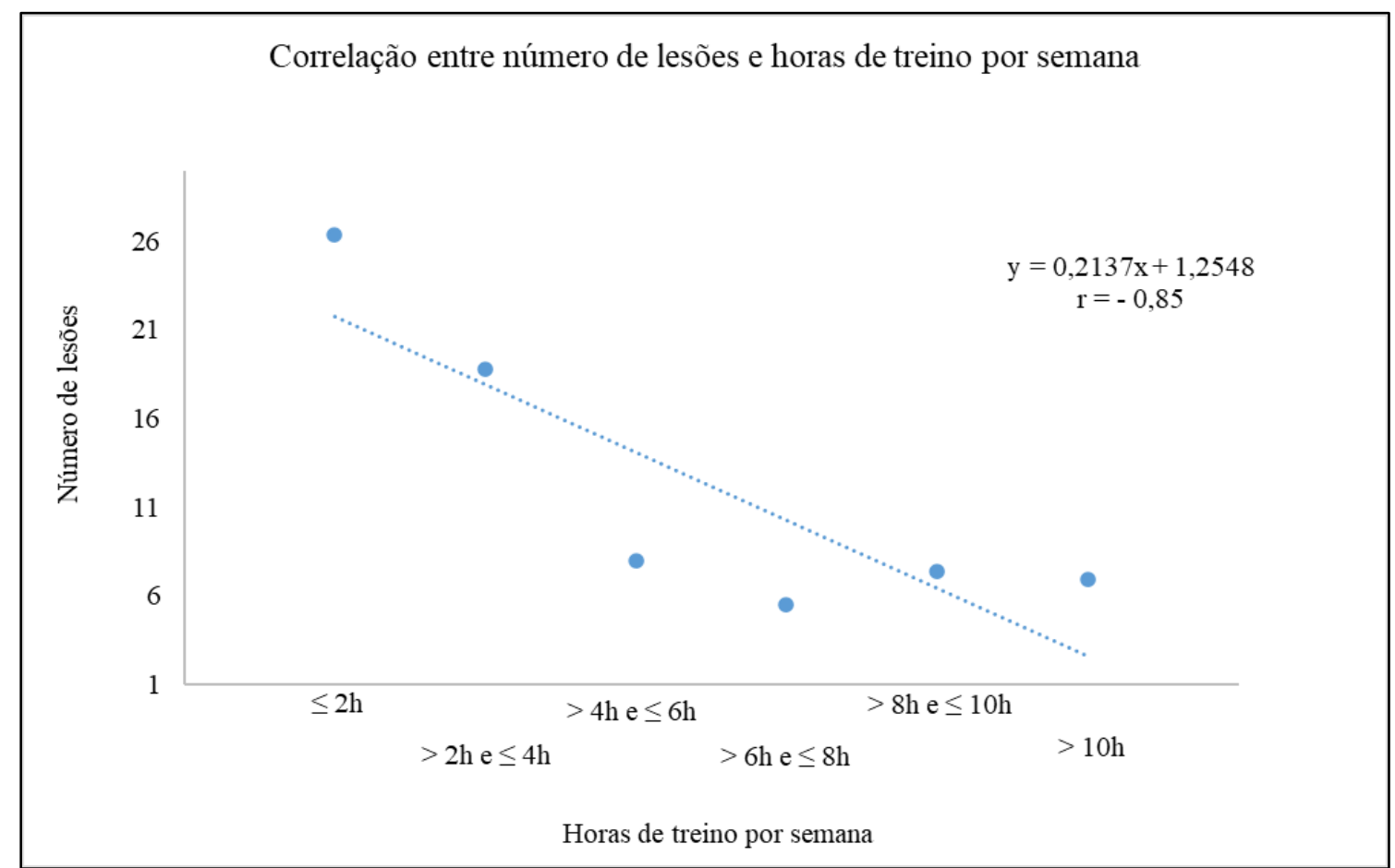

Figura 4. Correlação número de lesões por horas semanais de treinamento. 


\section{Borges et al.}

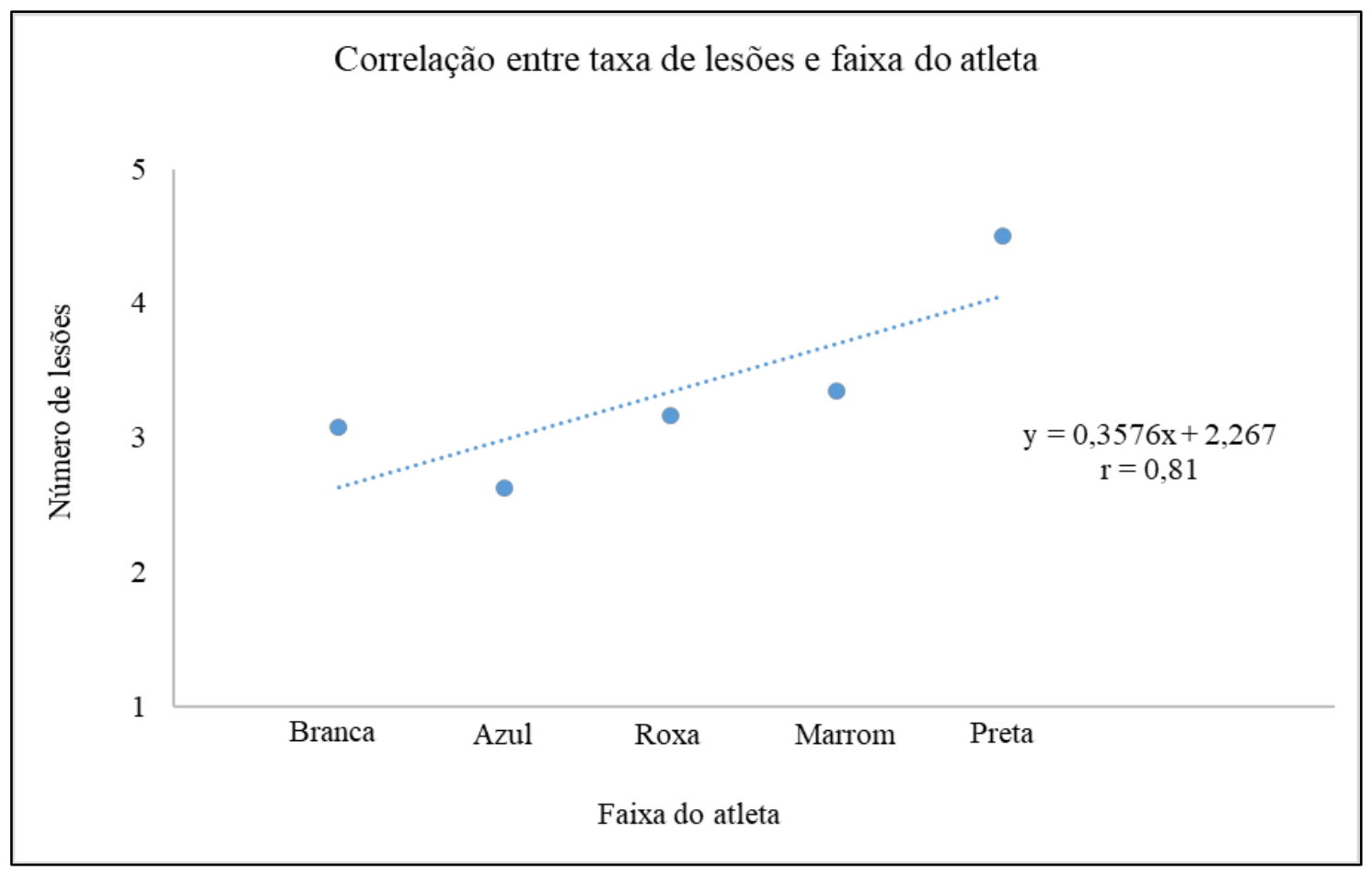

Figura 5. Correlação taxa de lesão por faixa de graduação do atleta.

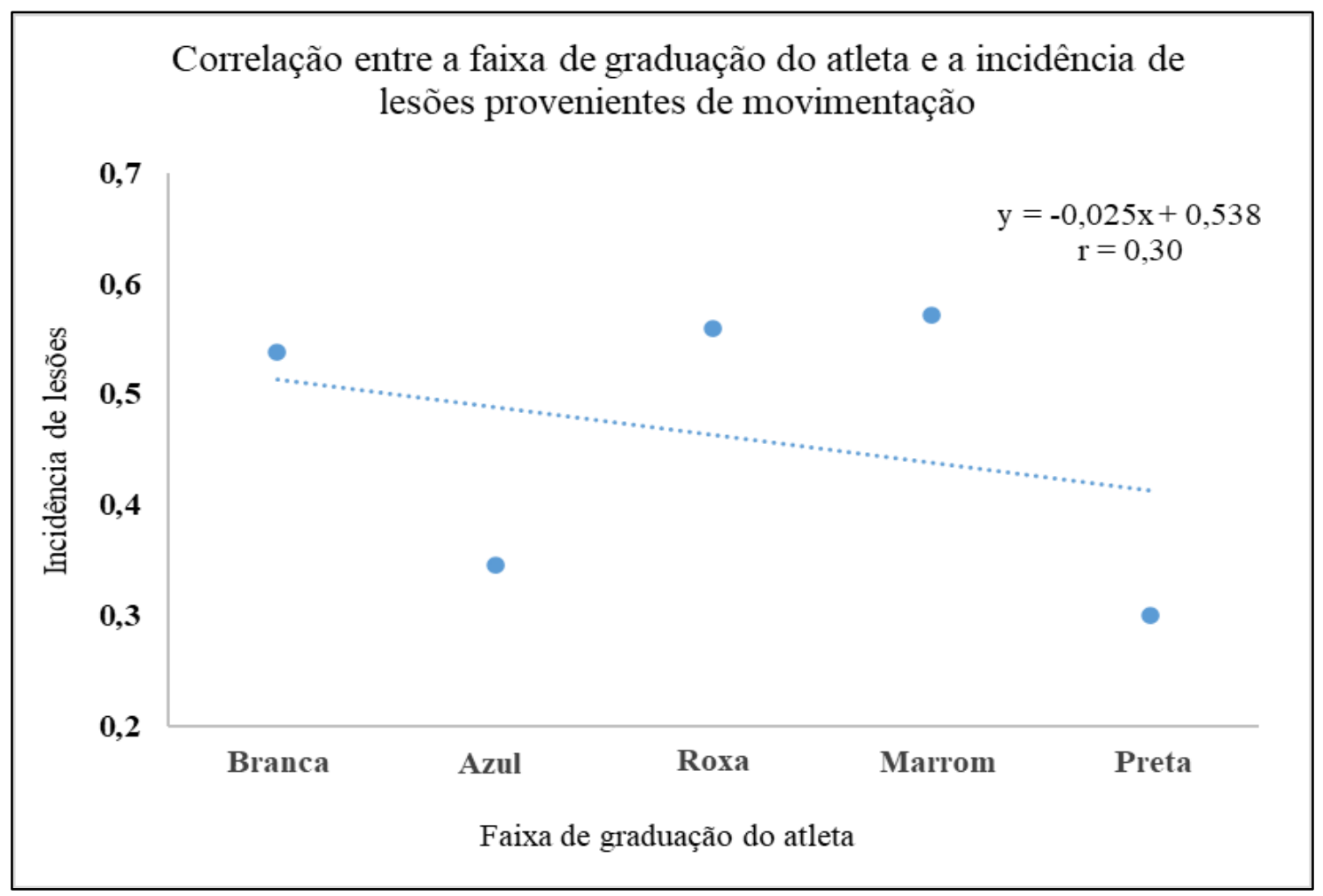

Figura 6. Correlação incidência de lesões provenientes de movimentação por faixa de graduação do atleta. 
Prevalência de lesões em atletas de jiu-jitsu

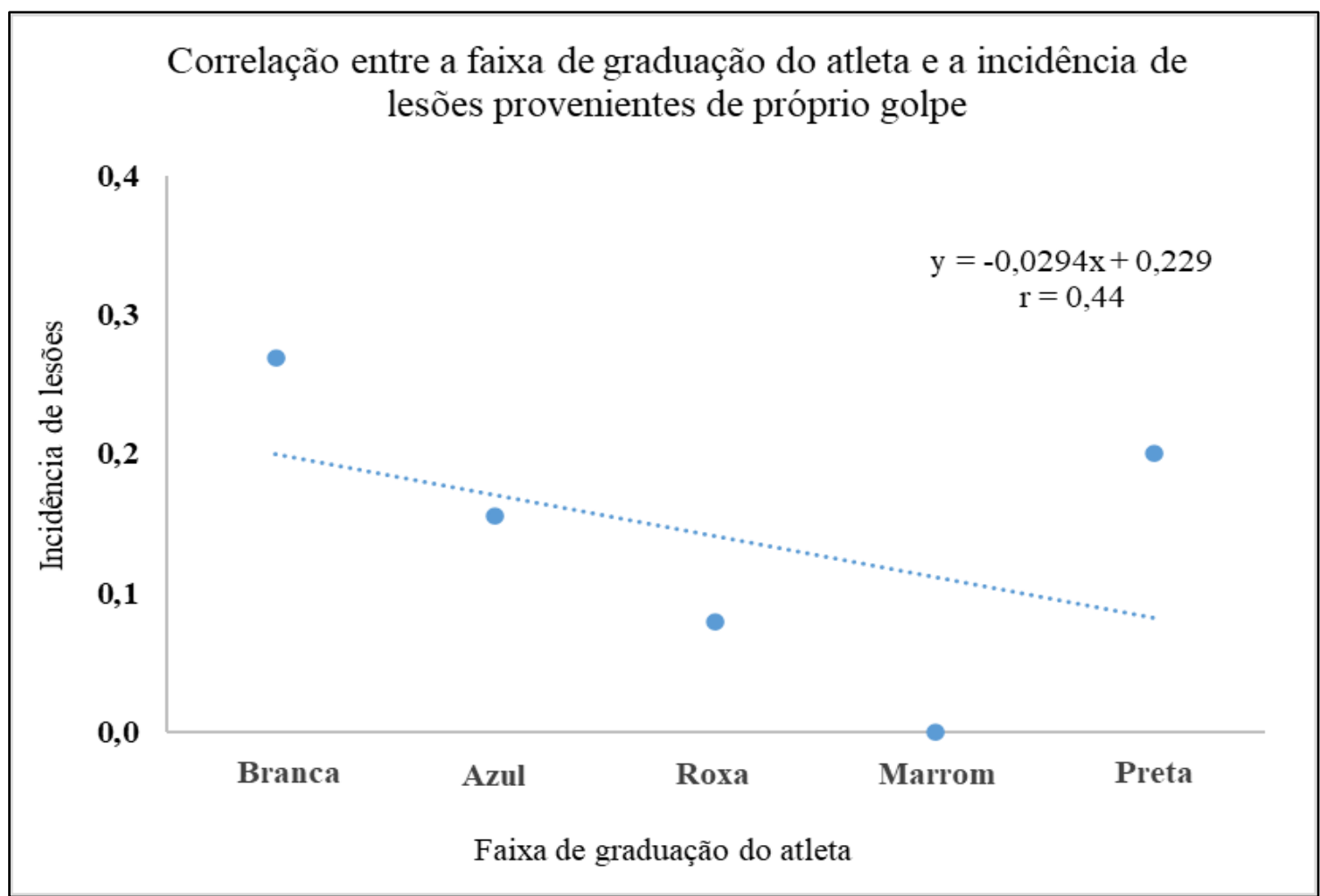

Figura 7. Correlação incidência de lesões provenientes de próprio golpe por faixa de graduação do atleta.

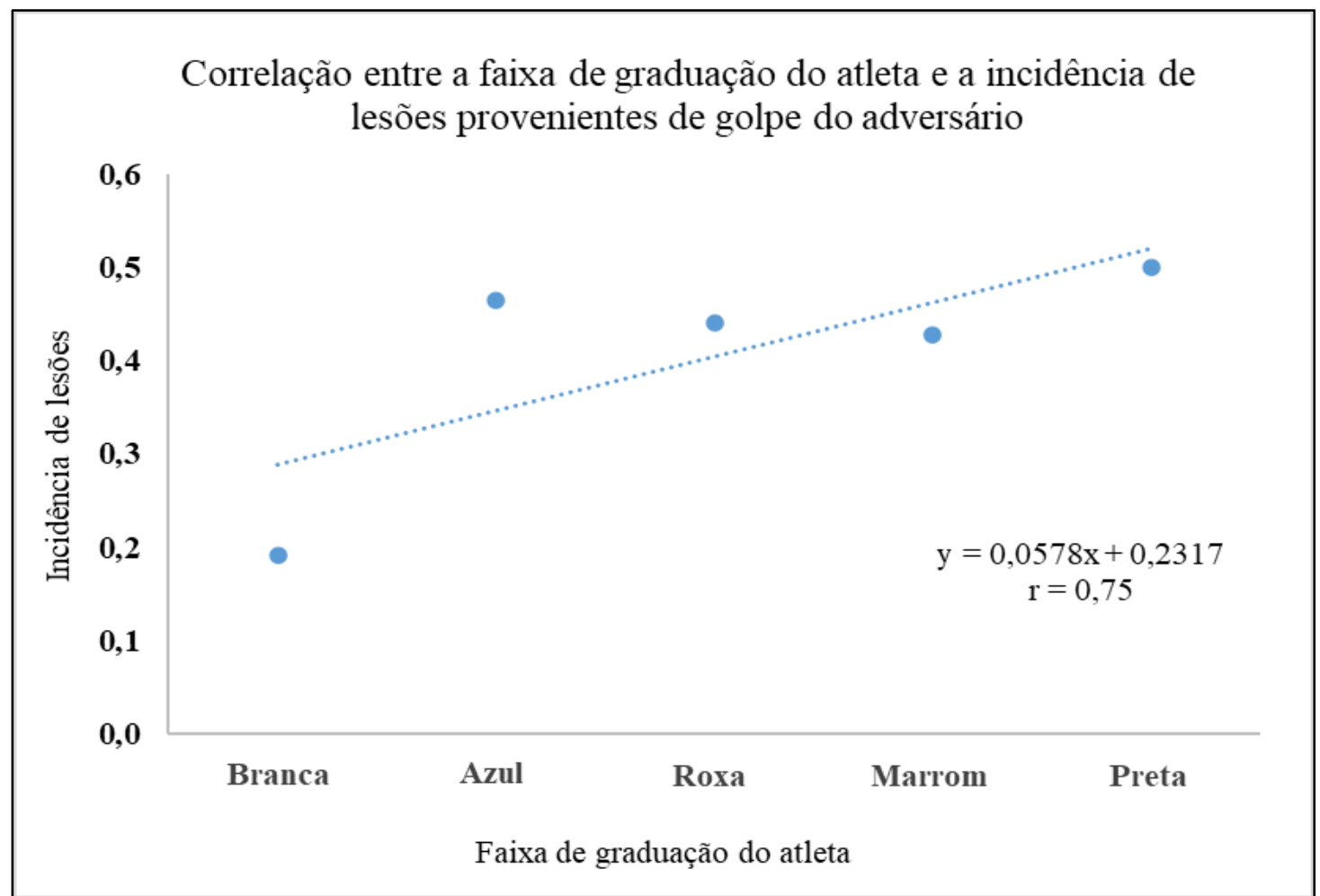

Figura 8. Correlação incidência de lesões provenientes de golpe do adversário por faixa de graduação do atleta. 